\title{
PELATIHAN MANAJEMEN USAHA BUDIDAYA KOPI SEBAGAI UPAYA PERBAIKAN TEKNIK BUDIDAYA DAN PENINGKATAN PEMAHAMAN PENCATATAN KEUANGAN USAHA
}

\section{FARMING MANAGEMENT TRAINING FOR COFFEE FARMER IN ORDER TO IMPROVE THE TECHNICAL SKILL OF FARMING AND FINANCIAL RECORDING}

\author{
Oleh: \\ Apri Andani, Redy Badrudin, dan M. Mustopa Romdhon \\ Jurusan Sosial Ekonomi Pertanian Universitas Bengkulu \\ apriandani82@gmail.com
}

\begin{abstract}
This activitiy has purposes to give a training about farming management, especially technical aspect and financial recording for coffee farming business. The target of this program is coffee farmers. The location is taken place in Baru Manis Village, Bermani Ulu Subdistrict, Rejang Lebong District, Bengkulu Province. The method used in this activity is extension approach method and combination with small group discussion and practice. The result show that farmers face many problem about their farming system. Their coffee has been attacted by some diseases that they never known before. After taken this activity they know that their plant are not always being attacted by pest, but some signs show that it is fungi or root disease. Furthermore, in financial aspect, they never take notes about how much money they have spent for their farming because they do not know how to write it in a good way. After taking this program, they learn how to record cost, price, and their return from their coffee. It can be said that this activity is needed and success.
\end{abstract}

Keywords: farming management, technical skill, financial record, coffee

\section{PENDAHULUAN}

Kopi merupakan komoditas perkebunan yang paling banyak diperdagangkan. Pusatpusat budidaya kopi ada di Amerika Latin, Amerika Tengah, Asia-pasifik dan Afrika. Sedangkan konsumen kopi terbesar ada di negara-negara Eropa dan Amerika Utara. Wajar bila komoditas ini sangat aktif diperdagangkan. Tanaman kopi sangat banyak jenisnya, bisa mencapai ribuan. Namun yang banyak dibudidayakan hanya empat jenis saja yakni arabika, robusta, liberika dan excelsa. Masing-masing jenis tersebut memiliki sifat yang berbeda-beda. Di Indonesia sendiri jenis kopi yang paling banyak dibudidayakan adalah Arabika dan Robusta. Memilih jenis tanaman untuk budidaya kopi, harus disesuaikan dengan tempat atau lokasi lahan. Lokasi lahan yang terletak di ketinggian lebih dari 800 meter dpl cocok untuk ditanami arabika. Sedangkan dari ketinggian 400-800 meter bisa ditanami robusta. Budidaya kopi didataran rendah bisa mempertimbangkan jenis liberika atau excelsa (Anonim, 2016). 


\section{METODE PENGABDIAN}

Kegiatan pengabdian ini dilaksanakan di Desa Baru Manis, Kecamatan Bermani Ulu, Kabupaten Rejang Lebong pada tanggal 27 Agustus 2016. Pelaksanaan kegiatan pengabdian dilakukan atas dasar permintaan dari Kepala Desa Baru Manis, yaitu Bapak Kusmin, karena adanya permasalahan terkait dengan budidaya tanaman kopi para petani di desa tersebut. Disamping itu, rendahnya pemahaman petani terhadap pembukuan keuangan usaha pertaniannya menjadi pertimbangan permintaan pengabdian ini dilakukan.

Kegiatan pengabdian dilakukan dengan pendekatan metode penyuluhan, diskusi kelompok kecil, dan latihan pembukuan keuangan.

Berikut adalah line-out materi penyuluhan teknik budidaya kopi (berkelanjutan) (Rainforest Alliance, 2013) (Prastowo, $d k k, 2010)$ dan pelatihan pencatatan keuangan usaha (Horngren, $d k k, 2000)$ yang disampaikan kepada petani sasaran.

\begin{tabular}{|c|c|c|}
\hline No & Materi & Tujuan Pemberian Materi \\
\hline \multicolumn{3}{|c|}{ Penyuluhan Teknik Budidaya Kopi } \\
\hline 1 & Persiapan Lahan & $\begin{array}{l}\text { Petani menjadi lebih paham bagaimana } \\
\text { proses pengolahan yang baik dan tidak } \\
\text { merusak lingkungan. }\end{array}$ \\
\hline 2 & Pemilihan Bibit & $\begin{array}{l}\text { Petani mengetahui bibit yang dinilai unggul } \\
\text { untuk dikembangkan. }\end{array}$ \\
\hline 3 & $\begin{array}{l}\text { Pemeliharaan } \\
\text { - Pemangkasan } \\
\text { - Penanganan Bahan Kimia } \\
\text { Secara Aman } \\
\text { - Pengelolaan Hama Terpadu }\end{array}$ & $\begin{array}{l}\text { Petani melakukan pemeliharaan dengan baik } \\
\text { dan benar serta tetap memperhatikan kaidah- } \\
\text { kaidah pertanian yang ramah lingkungan. }\end{array}$ \\
\hline 4 & Pemanenan & $\begin{array}{l}\text { Petani mengetahui kapan waktu yang tepat } \\
\text { untuk melakukan pemanenan dan bagaimana } \\
\text { cara pemanenan yang baik yang tidak } \\
\text { merusak tanaman. }\end{array}$ \\
\hline
\end{tabular}

Pelatihan Pencatatan Keuangan Usaha

1 Pencatatan Pengeluaran Keuangan Petani mengetahui bagaimana membuat Usahatani Kopi catatan sederhana tentang seberapa banyak uang yang telah dikeluarkan selama melakukan budidaya kopi.

2 Pencatatan Penerimaan Usahatani Petani menjadi bisa melakukan pencatatan Kopi penerimaan dari hasil penjualan kopi setelah panen.

3 Pembuatan Arus Kas Sederhana Petani dapat melakukan rekapan keuangan keluar dan keuangan yang masuk dari hasil usaha budidaya kopi yang dilakukan. 


\section{HASIL DAN PEMBAHASAN}

\section{Persiapan}

Dalam mempersiapkan kegiatan penyuluhan dan pelatihan, tim pengabdian dibantu oleh Mahasiswa Universitas Bengkulu yang sedang melaksanakan kegiatan Kuliah Kerja Nyata (KKN) di Desa Baru Manis Kecamatan Bermani Ulu Kabupaten Rejang Lebong. Disamping itu, Kepala Desa juga ikut membantu dalam mengundang warga agar mau berpartisipasi dalam kegiatan penyuluhan dimaksud.

Kegiatan dilaksanakan di Balai Desa Baru Manis yang letaknya di tengah lingkungan desa, sehingga mudah dijangkau oleh seluruh warga. Sementara, alat bantu yang digunakan dalam kegiatan penyuluhan adalah laptop, infocus, copy bahan materi penyuluhan dan pelatihan, serta kamera untuk keperluan dokumentasi.

\section{Pelaksanaan}

Penyuluhan dan Pelatihan

Kegiatan penyuluhan diawali dengan penyampaian materi tentang teknik budidaya kopi yang baik. Materi yang disampaikan merujuk pada Rainforest Alliance (2013), Panduan Implementasi Praktek Produksi Kopi Berkelanjutan; Menuju Sertifikasi Rainforest Alliance. Pemberian materi ini diharapkan dapat memberikan pemahaman kepada petani tidak hanya bagaimana menanam kopi yang baik dan berdaya hasil tinggi, tetapi juga tetap memperhatikan kaidah-kaidah ramah lingkungan sehingga pola budidaya yang diterapkan berkelanjutan baik secara materi maupun dari aspek lingkungan hidup.

Dari hasil diskusi, sebagian petani sudah menerapkan teknik pemeliharaan yang benar, yaitu memangkas cabang-cabang yang mengarah ke atas, namun pemangkasan tidak maksimal karena masih ada batang atas yang ditinggalkan dengan alas an agar tetap ada yang dipanen. Sementara dari aspek pemupukan, sebagian petani melakukan pemupukan secara rutin, namun sebagian lagi melakukan pemupukan ketika ada duit saja. Bahkan ada petani yang tidak pernah memberi pupuk pada usahatani kopinya. Tentu hal ini sangat berpengaruh terhadap produksi kopi yang dihasilkan. Hampir tidak ada petani yang mengaplikasikan pupuk organik.

Petani kopi yang ada di lokasi penyuluhan telah melakukan budidaya kopi secara turun temurun. Sehingga dari segi pengalaman, sebagian besar petani merupakan petani berpengalaman, rata-rata lebih dari 15 tahun. Kondisi ini yang dinilai akan sedikit menyulitkan dalam mengubah pola bercocok tanam yang baik. Namun, setidaknya penyuluhan yang disampaikan akan dapat memberikan pemahaman baru tentang pentingnya budidaya kopi yang tetap memperhatikan aspek lingkungan namun tetap menghasilkan. Diterapkan atau tidak ilmu yang disampaikan adalah menjadi hak sepenuhnya petani. Oleh karena itu, untuk menjamin ada atau tidaknya perubahan, perlu adanya pendampingan secara intensif kepada petani agar mau mengubah cara bercocok tanam yang selama ini dilakukan dengan pola yang baru yang lebih ramah terhadap lingkungan. 
Selain itu, proses pemanenan yang selama ini dilakukan petani pada umumnya salah. Tidak hanya salah dalam hal waktu panen, tetapi buah yang dipanen juga cenderung masih belum layak panen. Sebagian buah panen masih berwarna hijau. Teknik panen yang salah tentu akan mengakibatkan tanaman mudah rusak. Disamping itu, harga jual kopi yang diterima petani tidak akan tinggi karena kualitas yang dihasilkan juga tidak baik. Oleh karena itu, penyuluhan juga menyangkut materi bagaimana pemanenan yang baik, sehingga tidak merusakan tanaman dan hasil biji kopi yang dipanen bisa mendapatkan nilai yang tinggi.

Keluhan-keluhan juga disampaikan oleh petani terkait dengan tanaman kopi yang sedang dibudiayakan. Saat kegiatan pengabdian berlangsung, tanaman kopi warga Desa Baru Manis sedang terkena sejenis penyakit yang menyerang batang. Batang seperti kering dan berbubuk, lama-kelamaan batang akan kecoklatan, kulit pecah-pecah, kemudian mati.

Sesi berikutnya adalah pelatihan singkat pembukuan usaha budidaya tanaman kopi. Pada dasarnya yang disampaikan adalah bagaimana melakukan pencatatan transaksi keuangan yang berhubungan dengan usaha budidaya kopi yang sedang dijalakn oleh petani di Desa Baru Manis. Pelatihan ini memberikan pemahaman kepada petani tentang pentingnya memiliki catatan pembukuan usaha agar mereka bisa mengetahui seberap besar uang yang sudah dikorbankan untuk menjalankan usaha bercocok tanam kopinya, serta berapa banyak uang yang dihasilkan dari penjualan kopi. Sehingga para petani dapat dengan sendirinya menyimpulkan apakah usaha budidaya kopi yang dijalankan selama ini menguntungkan atau tidak.

\section{Evaluasi}

Kegiatan dinilai berhasil karena cukup baiknya respon dari warga selama mengikuti penyuluhan dan pelatihan. Kegiatan diikuti oleh petani yang seluruhnya adalah laki-laki. Partisipasi petani wanita tidak ada dalam kegiatan ini. Hal ini bisa saja dikarenakan kesibukan wanita di rumah, sudah ada kesepakatan dengan suami agar suami saja yang menghadiri penyuluhan, atau memang tidak ada ketertarikan untuk mengikuti penyuluhan ini. Beberapa warga mengajak untuk melihat perkebunan kopi yang dimilikinya dan menyampaikan keluh kesah terkait persoalan-persoalan yang dihadapai selama bercocok tanam kopi. Hal ini menunjukkan bahwa yang bersangkutan memberikan perhatian terhadap materi yang disampaikan oleh penyuluh.

\section{KESIMPULAN DAN SARAN}

Dari hasil pengabdian dapat disimpulkan bahwa masih banyak petani yang belum menerapkan sistem pertanian berkelanjutan terhadap budidaya tanaman kopi mereka. Begitu juga dengan catatan keuangan usaha. Hal ini disebabkan oleh rendahnya tingkat pengetahuan petani terhadap ilmu-ilmu tersebut. Setelah dilakukan pengabdian, pengetahuan petani terkait pola budidaya yang baik dan berkelanjutan menjadi lebih baik, demikian juga halnya dengan pengetahuan tentang catatan pembukuan usahatani mereka. 
Oleh karena itu, disarankan agar kegiatan pengabdian yang lebih intensif tentang teknik budidaya kopi yang berdaya hasil tinggi dan berkelanjutan menjadi penting untuk dilakukan. Pendampingan terhadap petani juga menjadi sebuah kebutuhan agar petani tidak berjalan sendiri dalam melakukan perubahan.

Ucapan terima kasih disampaikan kepada para petani di Desa Baru Manis Kecamatan Bermani Ulu Kabupaten Rejang Lebong atas partisipasi dan antusiasme yang cukup tinggi terhadap pelaksanaan kegiatan penyuluhan ini. Terima kasih juga disampaikan kepada mahasiswa KKN Unib periode Tahun 2016 yang telah menjadi fasilitator terlaksananya kegiatan pengabdian ini.

\section{DOKUMENTASI KEGIATAN}

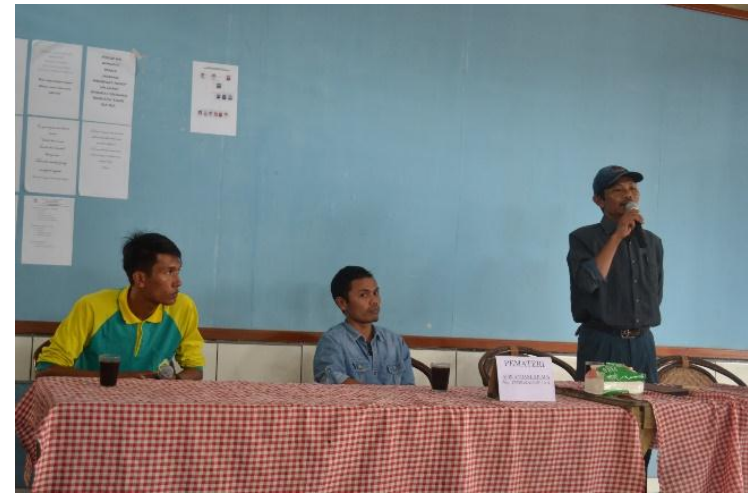

Gambar 1. Kepala Desa Baru Manis Memberikan Sambutan Kegiatan Penyuluhan

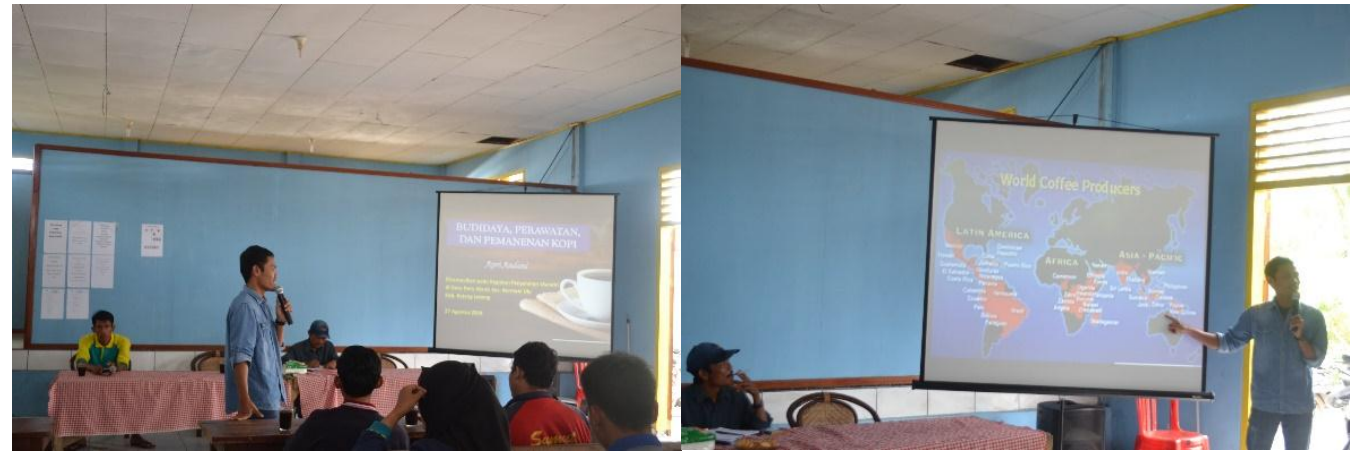

Gambar 2. Narasumber Menyampaikan Materi kepada Peserta Penyuluhan 


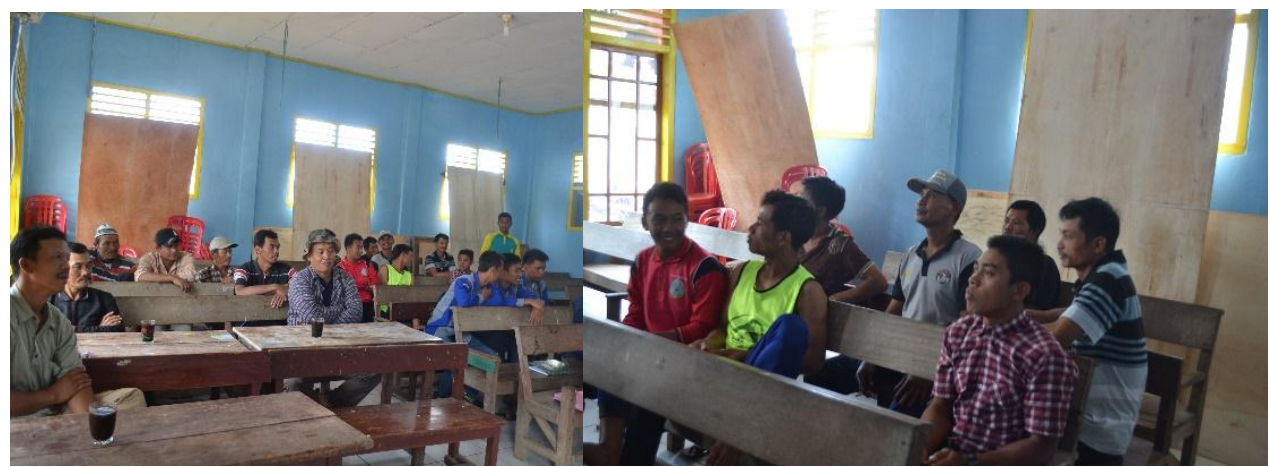

Gambar 3. Petani Peserta Penyuluhan Tampak Serius Memperhatikan Materi

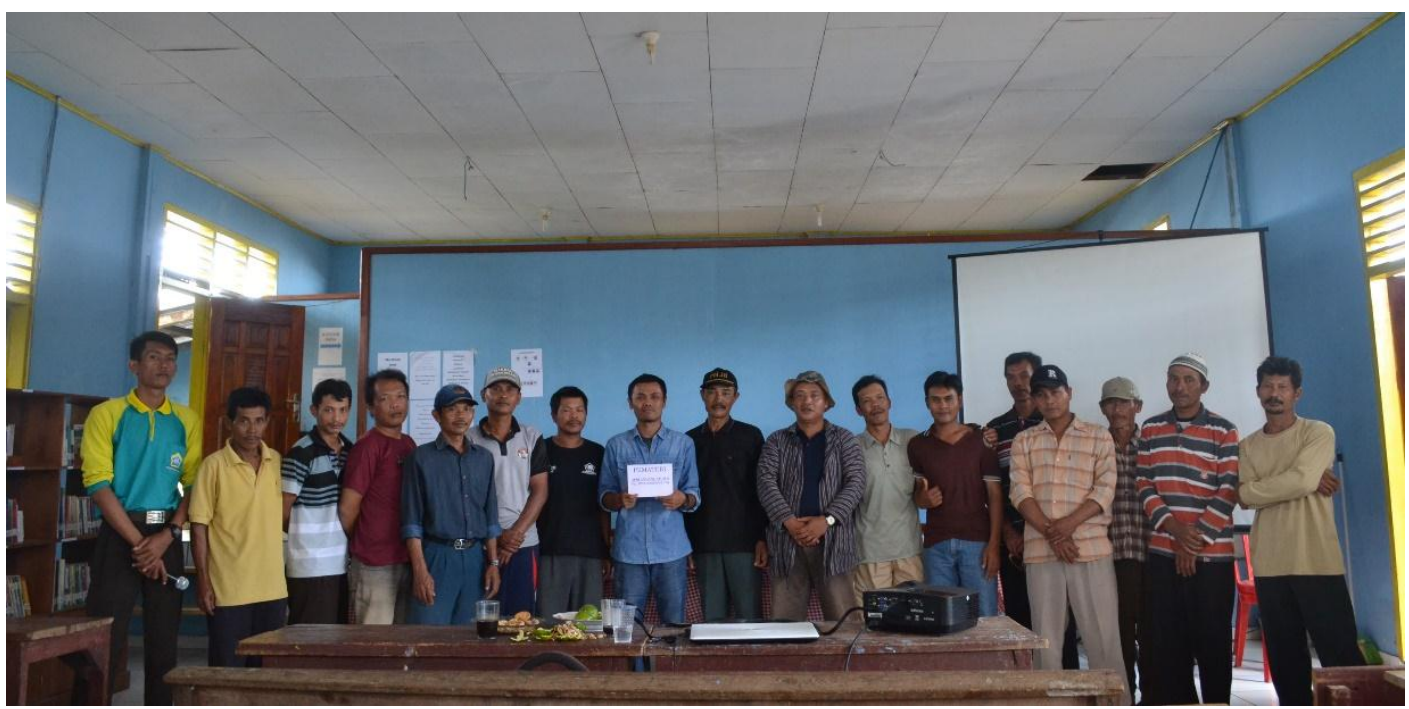

Gambar 4. Foto Bersama Narasumber dan Peserta Penyuluhan

\section{DAFTAR PUSTAKA}

Anonim, 2017, Panduan Teknis Budidaya Kopi, http://alamtani.com/budidaya-kopi.html (Diakses pada 12 Juli 2016).

Horngren, Charles T., Gary L. Sundern, John A. Elliot, 2000. Pengantar Akuntansi Keuangan; Edisi Keenam Jilid 2. Penerbit Erlangga. Jakarta.

Prastowo, B., E. Karmawati, Rubijo, Siswanto, C. Indrawanto, S.J. Munarso, 2010, Budidaya dan Pasca Panen Kopi, Pusat Penelitian dan Pengembangan Perkebunan. Bogor.

Rainforest Alliance, 2013, Panduan Implementasi Praktek Produksi Kopi Berkelanjutan; Menuju Sertifikasi Rainforest Alliance, Alliance Rainforest Printing. 